\title{
Is TV viewing an index of physical activity and fitness in overweight and normal weight children?
}

\author{
A Grund ${ }^{1}, \mathrm{H}$ Krause $^{2}, M$ Siewers $^{2}, \mathrm{H} \mathrm{Rieckert}^{2}$ and $\mathrm{M}$ Müller ${ }^{1, *}$ \\ ${ }^{1}$ Institut für Humanernährung und Lebensmittelkunde (Abteilung Ernährung des Menschen), Agrar- und \\ Ernährungswissenschaftliche Fakultät, Christian-Albrechts-Universität zu Kiel, Düsternbrooker Weg 17-19, \\ D-24105 Kiel, Germany: ${ }^{2}$ Institut für Sport und Sportwissenschaften (Abteilung Sportmedizin), Christian-Albrechts \\ Universität zu Kiel, Kiel, Germany
}

Submitted 15 February 2000: Accepted 2 May 2001

\begin{abstract}
Objective: To assess relationships between TV viewing and body composition, energy expenditure, physical activity, fitness and nutrition habits in prepubertal children.

Design: Cross-sectional study.

Subjects: Sixty prepubertal children (mean body mass index: $20.8 \mathrm{~kg} \mathrm{~m}^{-2}$, age: 5-11 years, overweight: $n=52$, normal weight: $n=8$ ).

Methods: TV consumption, socio-economic status (SES) and nutrition habits were estimated by questionnaires. Fat mass and fat-free mass were assessed by anthropometrics and bioelectrical impedance analysis, and resting energy expenditure by indirect calorimetry. Total energy expenditure was measured by a combination of indirect calorimetry and individually calibrated 24-hour heart rate (HR) monitoring. Activity-related energy expenditure and physical activity level were calculated. Aerobic fitness $\left(\mathrm{VO}_{2}\right.$ submax) was determined by ergometry, muscle strength (musculus quadriceps, musculus ischiocruralis) was measured by computer tensiometry. Children were stratified according to their daily TV consumption: $\leq 1 \mathrm{~h}$ of TV per day (group I) and $>1$ h of TV per day (group II).

Results: When compared with children of group I, children of group II had increased body weight, body mass index, skinfolds, fat mass and prevalence of overweight $(P<0.05$ and $<0.01$, respectively). By contrast, fat-free mass, energy expenditure, measures of physical activity and muscle strength were similar. Children of group II had normal absolute $\mathrm{VO}_{2}$ submax but reduced adjusted $\mathrm{VO}_{2}$ submax $(P<0.05)$. They also had parents with a lower educational level $(P<0.05)$. Similar nutritional habits were observed in both groups. There were no significant differences in the observed parameters between children with high (1-3 $\left.\mathrm{h} \mathrm{day}^{-1}\right)$ and very high $(>3 \mathrm{~h}$ day $^{-1}$ ) TV viewing.

Conclusions: There is a positive relationship between TV viewing and fatness. Increased TV viewing does not reflect reduced 24-hour energy expenditure as assessed by 24-hour HR monitoring, submaximal $\mathrm{VO}_{2}$, muscle strength or poor dietary intake. Increased TV consumption is associated with a low SES.
\end{abstract}

Keywords Physical inactivity Activity

Energy expenditure Childhood obesity Childhood nutrition
In Western societies overweight and obesity are epidemic and their incidence is increasing. Present data show that children are also getting fatter ${ }^{1-3}$. Environmental factors frequently discourage physical activity and promote overeating, thus supporting childhood obesity ${ }^{1-4}$. A low level of physical activity is considered as an increased risk factor of obesity ${ }^{1,5-9}$. Reduced physical activity results in a reduction in total energy expenditure (TEE), favouring a positive energy balance. However, the relationship between childhood obesity and energy expenditure or physical activity is far from clear. Obese subjects did not consistently show reduced activity ${ }^{10,11}$. Doubly labelled water (DLW) techniques, heart rate (HR) monitoring and accelerometers have been used to assess energy expenditure and physical activity directly in children and adults ${ }^{9,12-15}$. In addition to measures of physical activity, TV watching is frequently used as an index of physical inactivity in epidemiological and intervention studies ${ }^{5-8,16-21}$. Contrary to the direct assessment of energy expenditure and physical activity, this parameter showed a strong relationship with childhood obesity $^{16,22,23}$. However, there was no clear association 
Table 1 Characteristics of the study population

\begin{tabular}{|c|c|c|c|c|c|}
\hline \multirow{5}{*}{$\begin{array}{l}\text { Gender (boys/girls) } \\
\text { Prevalence of obesity (BMI>90th percentile) }(\%)^{*}\end{array}$} & \multicolumn{5}{|c|}{ Prepubertal children } \\
\hline & \multicolumn{2}{|c|}{ Group I $(n=25)$} & \multicolumn{2}{|c|}{ Group II $(n=35)$} & \multirow{4}{*}{$\frac{P}{P S} \frac{\mathrm{NS}}{P<0.01}$} \\
\hline & \multicolumn{2}{|c|}{$\begin{array}{c}10 / 15 \\
48.0\end{array}$} & \multicolumn{2}{|c|}{$\begin{array}{c}18 / 17 \\
97.1\end{array}$} & \\
\hline & & & & & \\
\hline & Mean \pm SD & Range & Mean \pm SD & Range & \\
\hline Age (years) & $7.0 \pm 1.4$ & $(4.8-11.4)$ & $7.3 \pm 1.6$ & $(5.2-11.5)$ & NS \\
\hline Body height $(\mathrm{cm})$ & $128.4 \pm 9.6$ & $(113.0-143.5)$ & $131.1 \pm 9.6$ & $(114.0-165.0)$ & NS \\
\hline Body weight (kg) & $31.5 \pm 9.9$ & $(19.6-52.0)$ & $38.7 \pm 12.2$ & $(26.7-89.0)$ & $P<0.05$ \\
\hline BMI $\left(\mathrm{kg} \mathrm{m}^{-2}\right) \dagger$ & $19.8 \pm 4.1$ & $(13.1-25.8)$ & $22.0 \pm 3.3$ & $(17.6-32.7)$ & $P<0.05$ \\
\hline TSF $(\mathrm{mm}) \ddagger$ & $17.3 \pm 7.8$ & $(6.0-32.0)$ & $22.6 \pm 6.5$ & $(11.7-39.0)$ & $P<0.05$ \\
\hline BSF $(\mathrm{mm}) \S$ & $13.3 \pm 7.0$ & $(4.0-31.0)$ & $18.2 \pm 6.0$ & $(6.7-30.0)$ & $P<0.05$ \\
\hline $\mathrm{ASF}(\mathrm{mm}) \boldsymbol{\eta}$ & $17.8 \pm 10.4$ & $(3.7-32.0)$ & $27.8 \pm 10.0$ & $(15.7-54.7)$ & $P<0.01$ \\
\hline SIF (mm)\| & $17.4 \pm 11.9$ & $(3.3-44.0)$ & $29.4 \pm 9.6$ & $(14.0-62.3)$ & $P<0.01$ \\
\hline $\operatorname{SSF}(\mathrm{mm})^{\star *}$ & $14.3 \pm 8.4$ & $(4.0-35.0)$ & $22.2 \pm 8.9$ & $(9.0-47.7)$ & $P<0.01$ \\
\hline$\Sigma$ TSF, BSF, SIF, SSF $(\mathrm{mm}) \dagger \dagger$ & $62.3 \pm 34.2$ & $(20.0-141.0)$ & $92.3 \pm 28.2$ & $(51.3-166.3)$ & $P<0.01$ \\
\hline Weight/height ratio & $0.9 \pm 0.1$ & $(0.8-1.1)$ & $0.9 \pm 0.1$ & $(0.8-1.1)$ & NS \\
\hline$R(\Omega) \neq \ddagger$ & $718.0 \pm 70.7$ & $(572.0-849.0)$ & $704.4 \pm 58.4$ & $(563.0-871.0)$ & NS \\
\hline$X C(\Omega) \S \S$ & $65.8 \pm 6.4$ & $(55.0-81.0)$ & $68.6 \pm 7.8$ & $(50.0-80.0)$ & NS \\
\hline Fat mass (\%)ๆ१ & $24.5 \pm 7.9$ & $(10.5-38.1)$ & $30.7 \pm 4.9$ & $(20.9-41.6)$ & $P<0.01$ \\
\hline Fat mass (kg) ๆ१ & $8.2 \pm 4.4$ & $(2.2-16.3)$ & $12.1 \pm 4.8$ & $(6.3-30.2)$ & $P<0.01$ \\
\hline Fat-free mass (\%)११ & $75.5 \pm 7.9$ & $(61.9-89.5)$ & $69.1 \pm 4.9$ & $(58.4-79.1)$ & $P<0.01$ \\
\hline Fat-free mass $(\mathrm{kg})$ ๆी & $23.4 \pm 6.4$ & $(16.6-35.7)$ & $26.6 \pm 7.9$ & $(17.7-58.8)$ & NS \\
\hline
\end{tabular}

Mean \pm standard deviation (range), $P=$ significance level, $\mathrm{NS}=$ not significant; group I = children who watch $<1 \mathrm{~h}$ of $\mathrm{TV}$ per day, group $\mathrm{II}=$ children who watch $>1 \mathrm{~h}$ of TV per day.

* 90 th BMI percentile according to Hesse ${ }^{31}$.

$\dagger \mathrm{BMI}=$ body mass index.

$\ddagger$ TSF $=$ triceps skinfold.

$\S \mathrm{BSF}=$ biceps skinfold.

I $\mathrm{ASF}=$ abdominal skinfold.

$\|$ SIF = suprailiacal skinfold.

** SSF $=$ subscapular skinfold.

†† Sum of $\dagger, \ddagger$, ๆ and $\|$.

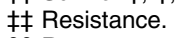

$\S \S$ Reactance.

ๆๆ Measured by bioelectrical impedance and anthropometry, calculated according to Goran et al. ${ }^{33}$.

between measures of physical activity and time spent watching $\mathrm{TV}^{22-24}$. Other studies showed an association between TV watching and nutrition habits. The consumption of sweets, cakes and fast foods increased with increased TV viewing ${ }^{20,25-27}$. These data suggest that other lifestyle factors associated with TV viewing but not reduced energy expenditure may explain the increased prevalence of overweight and obesity in children. On the other hand, Robinson mentioned that watching more TV could also be a consequence of being overweight ${ }^{28}$.

We conclude that the association between TV watching and overweight is unclear in children. We therefore investigated the relationship between body composition and various aspects of physical activity, energy expenditure and fitness (24-hour energy expenditure (TEE), resting energy expenditure (REE), physical activity, fitness, muscle strength, nutrition habits) in prepubertal overweight and normal weight children differing with respect to time spent viewing TV.

\section{Materials and methods}

\section{Subjects}

Sixty prepubertal children (28 boys, 32 girls) between 5 and 11 years old were examined in Kiel between July
1998 and August 1999. The group of children was a random sample. Pubertal stage was assessed by school physicians using Tanner's puberty rating. The prepubertal stages were mode 1 and 2. Measurements of body composition and energy expenditure were done at the Institute of Human Nutrition and Food Science and the Institute of Sport and Sport Science (Department of Sport Medicine) at the Christian-Albrechts-Universität zu Kiel (CAU) (Tables 1 and 2). The procedures had been explained to all parents and children. Detailed information about the physical activity and nutrition of their children, as well socio-economic factors, were given by the parents (Tables 3 and 4). A food-frequency questionnaire was used according to the WHO-MONICA project as described previously ${ }^{29}$.

Children were stratified according to their daily TV consumption (mean TV viewing time: $1.7 \pm 1.0 \mathrm{~h} \mathrm{day}^{-1}$ ): group I $(n=25)$ watched $\leq 1 \mathrm{~h}$ of TV per day, group II $(n=35)$ watched $>1$ h of TV per day. The stratification was chosen in accordance with the Third National Health and Nutrition Examination Survey ${ }^{16}$. TV consumption was assessed by questionnaire. The question was: 'How many hours per day does your child watch TV?' The answer was given by parents as a continuous variable. 
Table 2 Energy expenditure (EE), physical activity, aerobic fitness $\left(\mathrm{VO}_{2}\right.$ max) and muscle strength of prepubertal children

\begin{tabular}{|c|c|c|c|c|c|}
\hline & \multicolumn{4}{|c|}{ Prepubertal children } & \multirow[b]{3}{*}{$t$-test $(P$} \\
\hline & \multicolumn{2}{|c|}{ Group I $(n=25)$} & \multicolumn{2}{|c|}{ Group II $(n=35)$} & \\
\hline & Mean \pm SD & Range & Mean \pm SD & Range & \\
\hline $\operatorname{REE}(\mathrm{MJ} / 24 \mathrm{~h})^{\star}$ & $5.0 \pm 0.9$ & $(3.6-7.2)$ & $5.0 \pm 0.7$ & $(3.8-7.3)$ & NS \\
\hline REE adjusted (MJ/24 h)† & $5.3 \pm 0.6$ & $(4.3-6.5)$ & $5.0 \pm 0.5$ & $(4.2-6.1)$ & NS \\
\hline TEE $(M J / 24 \mathrm{~h}) \ddagger$ & $7.5 \pm 2.9$ & $(4.5-15.0)$ & $7.0 \pm 1.7$ & $(4.8-11.1)$ & NS \\
\hline TEE adjusted (MJ/24 h)§ & $8.2 \pm 2.3$ & $(5.4-14.1)$ & $7.1 \pm 1.3$ & $(4.5-11.6)$ & NS \\
\hline AEE (MJ/24 h)ף & $2.2 \pm 2.3$ & $(-0.01-8.6)$ & $1.6 \pm 1.3$ & $(0.0-4.7)$ & NS \\
\hline PAL (TEE/REE)\| & $1.5 \pm 0.4$ & $(1.0-2.7)$ & $1.4 \pm 0.3$ & $(1.0-1.9)$ & NS \\
\hline Time $>$ FLEX-HR $(\%)^{\star \star}$ & $23.7 \pm 13.6$ & $(4.3-47.3)$ & $20.2 \pm 14.1$ & $(2.7-64.6)$ & NS \\
\hline $\mathrm{Fa} \max (\mathrm{N}) \dagger \dagger$ & $229.4 \pm 99.7$ & $(60.8-483.6)$ & $261.0 \pm 96.0$ & $(60.9-501.2)$ & NS \\
\hline $\mathrm{Fb} \max (\mathrm{N}) \ddagger \ddagger$ & $112.1 \pm 53.9$ & $(24.5-304.2)$ & $136.5 \pm 64.7$ & $(24.5-304.2)$ & NS \\
\hline $\mathrm{VO}_{2} \operatorname{submax}\left(I \min ^{-1}\right) \S \S$ & $0.9 \pm 0.3$ & $(0.5-1.8)$ & $1.0 \pm 0.4$ & $(0.0-2.4)$ & NS \\
\hline $\mathrm{O}_{2}$-pulse $(\mathrm{ml} / \mathrm{bpm})$ ११ & $5.6 \pm 1.7$ & $(3.2-10.4)$ & $6.0 \pm 2.2$ & $(2.9-14.3)$ & NS \\
\hline RER submax $\|\tilde{\|}\|$ & $1.09 \pm 0.07$ & $(0.95-1.25)$ & $1.11 \pm 0.06$ & $(1.9-1.26)$ & NS \\
\hline
\end{tabular}

Mean \pm standard deviation (range), $P=$ significance level, NS = not significant; group I = children who watch $<1 \mathrm{~h}$ of TV per day, group II = children who watch $>1 \mathrm{~h}$ of TV per day.

* Resting energy expenditure measured by indirect calorimetry.

† Resting energy expenditure measured adjusted for fat-free mass according to Ravussin and Bogardus ${ }^{21}$.

$\ddagger$ Total energy expenditure measured by 24 -hour HR monitoring.

\$ Total energy expenditure measured adjusted for fat-free mass according to Ravussin and Bogardus ${ }^{21}$

In AEE calculated from the difference between TEE and REE minus $5 \%$ of TEE for diet-induced thermogenesis.

\| Physical activity level (PAL = TEE/REE).

${ }^{* *}$ Time of the day in per cent when heart rate is above FLEX-HR.

t† Maximal isometrical strength in musculus quadriceps.

隹 Maximal isometrical strength in musculus ischiocruralis.

$\S \S \mathrm{VO}_{2}$ submax = submaximal oxygen consumption calculated at a fixed $\mathrm{HR}$ from $170 \mathrm{bpm}$.

१ๆ $\mathrm{O}_{2}$-pulse $=$ ratio of submaximal oxygen consumption and heart rate.

IIII RER submax = submaximal respiratory exchange ratio calculated at a fixed HR from $170 \mathrm{bpm}$.

The parents gave their informed written consent. The ethical committee of the CAU had approved the study.

\section{Measurement of body composition}

Body composition was measured by anthropometric methods (body weight, body height, and triceps, biceps, abdominal, suprailiacal and supscapular skinfolds) and by bioelectrical impedance analysis (BIA) (Multi-Frequency Analyser 2000-M, Data Input GmbH, Frankfurt/M,
Germany) as described previously ${ }^{30}$. One investigator (A.G.) performed all measurements. The nutritional status of the children was defined by using body mass index (BMI) percentiles according to Hesse ${ }^{31}$ : overweight $=>90$ th and normal weight $=<90$ th -10 th percentile. As reference, age-specific BMI percentiles from an actual and representative German database of children and adolescents aged 1 to 18 years were used ${ }^{31}$. The standard measurement $(50 \mathrm{kHz}, 800 \mathrm{~mA})$ was used for

Table 3 Socio-demographic characteristics of study population

\begin{tabular}{|c|c|c|c|}
\hline & Group I $(n=25)$ & Group II $(n=35)$ & Chi-square $(P)$ \\
\hline Nationality of the parents & & & NS \\
\hline German & $20(80.0 \%)$ & $26(74.3 \%)$ & \\
\hline Other country & $5(20.0 \%)$ & $9(25.7 \%)$ & \\
\hline Education of the mother & & & $P<0.05$ \\
\hline Junior high school & $5(20.0 \%)$ & $18(51.4 \%)$ & \\
\hline Modern secondary school & $8(32.0 \%)$ & $12(34.3 \%)$ & \\
\hline Secondary school & $10(40.0 \%)$ & $3(8.6 \%)$ & \\
\hline No answer & $2(8.0 \%)$ & $2(5.7 \%)$ & \\
\hline Education of the father & & & $P<0.05$ \\
\hline Junior high school & $11(44.0 \%)$ & $20(57.1 \%)$ & \\
\hline Modern secondary school & $4(16.0 \%)$ & $2(5.7 \%)$ & \\
\hline Secondary school & $9(36.0 \%)$ & $3(8.6 \%)$ & \\
\hline No answer & $1(4.0 \%)$ & $10(28.6 \%)$ & \\
\hline Monthly income spent on food & & & NS \\
\hline$>33 \%$ & $12(48.0 \%)$ & $17(48.6 \%)$ & \\
\hline$<33 \%$ & $12(48.0 \%)$ & $9(25.7 \%)$ & \\
\hline No answer & $1(4.0 \%)$ & $9(25.7 \%)$ & \\
\hline Membership in a sports club & & & NS \\
\hline Yes & $14(56.0 \%)$ & 15 (42.9\%) & \\
\hline No & $11(44.0 \%)$ & $20(57.1 \%)$ & \\
\hline
\end{tabular}

Mean (percentage), $P=$ significance level, NS = not significant; group I = children who watch $<1 \mathrm{~h}$ of TV per day, group II $=$ children who watch $>1 \mathrm{~h}$ of TV per day. 
Table 4 Food frequency data of the prepubertal children

\begin{tabular}{|c|c|c|c|c|c|c|c|c|c|}
\hline \multirow[b]{2}{*}{ Foods } & \multicolumn{2}{|c|}{ Daily } & \multicolumn{2}{|c|}{ 2-4 times per week } & \multicolumn{2}{|c|}{1 time per week } & \multicolumn{2}{|c|}{ Seldom or never } & \multirow{2}{*}{$\begin{array}{c}\text { Chi-square } \\
(P)\end{array}$} \\
\hline & Group I & Group II & Group I & Group II & Group I & Group II & Group I & Group II & \\
\hline Wholemeal bread & $15(60.0 \%)$ & $20(57.1 \%)$ & $6(24.0 \%)$ & $6(17.1 \%)$ & $2(8.0 \%)$ & $5(14.3 \%)$ & $2(8.0 \%)$ & $4(11.4 \%)$ & NS \\
\hline White bread & $13(52.0 \%)$ & $13(37.1 \%)$ & $6(24.0 \%)$ & 11 (31.0\%) & $2(8.0 \%)$ & $6(17$. & $4(16.0 \%)$ & $5(14.2 \%)$ & \\
\hline Muesli & $8(32.0 \%)$ & $1(2.9 \%)$ & $0(0.0 \%)$ & $12(34.3 \%)$ & $9(36.0 \%)$ & $8(22.8 \%)$ & $8(32.0 \%)$ & $14(40.0 \%)$ & $P<0.05$ \\
\hline $\begin{array}{l}\text { Special yoghurt for } \\
\text { children }\end{array}$ & $4(16.0 \%)$ & $8(22.9 \%)$ & $9(36.0 \%)$ & $17(48.6 \%)$ & $3(12.0 \%)$ & $3(8.6 \%)$ & $9(36.0 \%)$ & $7(20.0 \%)$ & NS \\
\hline Noodles/spaghetti & $3(12.0 \%)$ & $7(20.0 \%)$ & 7 (26.0\%) & $22(62.9 \%)$ & 12 (48.0\%) & $4(11.4 \%)$ & $2(8.0 \%)$ & $2(5.7 \%)$ & $P<0.05$ \\
\hline Potatoes & $6(24.0 \%)$ & $10(28.6 \%)$ & $12(48.0 \%)$ & $20(57.1 \%)$ & $5(20.0 \%)$ & $5(11.4 \%)$ & $2(8.0 \%)$ & $2.9 \%)$ & NS \\
\hline Fruit & $14(56.0 \%)$ & $20(57.1 \%)$ & $7(28.0 \%)$ & $10(28.6 \%)$ & $2(8.0 \%)$ & $2(5.7 \%)$ & $2(8.0 \%)$ & $3(8.6 \%)$ & NS \\
\hline Vegetables & $12(48.0 \%)$ & $14(40.0 \%)$ & $6(24.0 \%)$ & $14(40.0 \%)$ & $5(20.0 \%)$ & $4(11.4 \%)$ & $2(8.0 \%)$ & $4(8.6 \%)$ & NS \\
\hline Meat/sausage & $8(32.0 \%)$ & $10(28.6 \%)$ & $7(26.0 \%)$ & $18(51.4 \%)$ & $6(20.0 \%)$ & $5(11.4 \%)$ & $2(8.0 \%)$ & $3(8.6 \%)$ & NS \\
\hline French fries & $0(0.0 \%)$ & & $0(0$. & 5 (14.3\%) & $10(40.0 \%)$ & $9(25.7 \%)$ & $15(60.0 \%)$ & $19(54$. & \\
\hline Pizza & $0(0.0 \%)$ & $2(8.0 \%)$ & $0(0.0 \%)$ & $1(2.9 \%)$ & $9(36.0 \%)$ & $13(37.1 \%)$ & $16(64.0 \%)$ & 19 (54.3\%) & NS \\
\hline Chocolate-crème & $5(20.0 \%)$ & $6(24.0 \%)$ & $5(20.0 \%)$ & $11(31.0 \%)$ & $5(20.0 \%)$ & $9(25.7 \%)$ & $10(40.0 \%)$ & $9(25.7 \%)$ & NS \\
\hline Sweets & $9(36.0 \%)$ & $9(25.7 \%)$ & $6(24.0 \%)$ & 15 (42.9\%) & $6(24.0 \%)$ & $5(11.4 \%)$ & $5(20.0 \%)$ & $6(24.0 \%)$ & NS \\
\hline Chips, etc. & $3(12.0 \%)$ & $5(14.3 \%)$ & $4(16.0 \%)$ & $4(11.4 \%)$ & $9(36.0 \%)$ & $10(28.6 \%)$ & $9(36.0 \%)$ & $16(45.7 \%)$ & NS \\
\hline Lemonade & 5 (14.3\%) & $1(7.1 \%)$ & $6(17.1 \%)$ & $6(42.9 \%)$ & $4(11.4 \%)$ & $4(28.6 \%)$ & 20 (57.1\%) & $7(50.0 \%)$ & NS \\
\hline
\end{tabular}

Mean (percentage), $P=$ significance level, NS = not significant; group I = children who watch $<1 \mathrm{~h}$ of TV per day, group II $=$ children who watch $>1 \mathrm{~h}$ of TV per day.

BIA. The measurements took place in the morning after an overnight fast of $8-12 \mathrm{~h}$ and after voiding ${ }^{30}$. In a previous study we compared BIA-derived fat mass with fat mass as assessed by anthropometric measures in 610 children aged 5-7 years. In that study BIA data systematically overestimated anthropometrically derived fat mass at low fat mass whereas the opposite was true at high fat mass $^{30}$. To overcome the problem a combination of anthropometric and BIA data was used in this study as proposed recently by Goran et al. ${ }^{33}$, who used dualenergy x-ray absorptiometry (DEXA) as a reference method. The following formula was used to calculate fat-free mass (FFM):

$$
\begin{aligned}
\text { FFM }(\mathrm{kg})=[ & \left.0.16 \times\left(\text { height }^{2} / R\right)\right]+(0.67 \times \text { weight }) \\
& -(0.11 \times \text { triceps skinfold }) \\
& -(0.16 \times \text { subscapular skinfold }) \\
& +(0.43 \times \text { sex })+2.41 \mathrm{~kg},
\end{aligned}
$$

where height is in $\mathrm{cm}$, weight in $\mathrm{kg}$, triceps skinfold in $\mathrm{mm}$, subscapular skinfold in $\mathrm{mm}$, and sex is 0 for girls and 1 for boys.

Recalculating our previous data by use of this formula showed a marked reduction of the systematic deviation (data not shown). However, when compared with anthropometric data, there was still some over/underestimation of fat mass by use of the combined method at low/high fat mass (data not shown).

\section{Measurement of REE}

Resting energy expenditure was measured in the morning, after the children arrived in an overnight fasting state (i.e. 8-12 h after their last meal). Measurements were performed by indirect calorimetry (IC) continuously for $1 \mathrm{~h}$ with the use of GEM (gas exchange measurement;
Europa Scientific, Crewe, UK) (Table 2). The subjects were emotionally relaxed and the environment was thermoneutral $^{32}$. To eliminate the effect of FFM, REE was adjusted according to Ravussin and Bogardus ${ }^{21}$ : the calculated value of the regression analysis minus measured REE plus mean group REE was used to adjust $\mathrm{REE}^{21,34}$ (Table 2). Resting heart rate was measured with a heart rate monitor (Physio-Trend, med-NATIC, Munich, Germany) (see below).

\section{Ergospirometry}

Physical fitness, which was defined as submaximal oxygen consumption $\left(\mathrm{VO}_{2}\right.$ submax), was measured by ergospirometry. The individual relationship between heart rate and oxygen consumption $\left(\mathrm{VO}_{2}\right)$ made it necessary to establish an individual regression line for $\mathrm{HR}$ vs. $\mathrm{VO}_{2}$ for each child on a bicycle ergometer (Ergostar, PMS Professional Medical Systems, Basel, Switzerland) ${ }^{35,36}$. The workloads were calculated depending on the weight of the children ${ }^{37}$. The protocol started with a workload of $0.5 \mathrm{~W}$ per kg body weight. Workload was increased by $0.5 \mathrm{~W}$ per kg body weight every 2-3 $\mathrm{min}^{37}$. The measurements lasted for 10 to $12 \mathrm{~min}$. The workload was increased when $\mathrm{HR}$ and $\mathrm{VO}_{2}$ reached a plateau at the respective workload. The relationship between $\mathrm{HR}$ and $\mathrm{VO}_{2}$ was used to calculate 24-hour energy expenditure from 24-hour HR monitoring during free-living conditions (Table 2). Maximal workload was not reached in the test. Measurements by ergospirometry were stopped approximately at a heart rate of about 175 beats per minute (bpm). At a fixed HR from $170 \mathrm{bpm}$, $\mathrm{VO}_{2}$ submax, the ratio of submaximal oxygen consumption and heart rate $\left(\mathrm{O}_{2}\right.$-pulse) and the submaximal respiratory exchange ratio (RER submax) during exercise were used as indices for aerobic fitness ${ }^{38,39}$. $\mathrm{VO}_{2}$ submax and $\mathrm{O}_{2}$-pulse were adjusted for body weight and body 
weight ${ }^{0.75}$. RER was used as a body-mass-independent parameter of aerobic fitness.

\section{HR monitoring}

The heart rate monitor was fixed with three standard electrodes at the thorax of the children. Measurements were performed continuously (minute-by-minute) during 24 hours. The intra-individual day-to-day variation was tested in a subgroup of six children (three boys, three girls) by measurements on three different days (two days in the week, one at the weekend) and was found to be low (coefficient of variation $(\mathrm{CV})=2.1-5.5 \%$ ). There was a tendency for higher TEE values during the weekend. However, the correlation between TEE assessed at a weekday and TEE measured at the weekend was very strong $(R=0.95)$. The HR monitor saved the 24-hour HR data. In the present study 'FLEX-HR' was defined as the mean of the highest HR during sitting on the bicycle ergometer and the lowest HR during light working on the ergometer. Individually FLEX-HR was used to discriminate between resting and exercise HR. Total energy expenditure was measured by the FLEX-HR monitoring method as described previously ${ }^{40,41}$. For the remainder of the daytime, when HR was above FLEX-HR, energy expenditure was derived from the minute-by-minute recorded HR using the individual child's regression line for the $\mathrm{VO}_{2}$ corresponding to $\mathrm{HR}^{15}$. The activity-related energy expenditure (AEE) was calculated from the difference between TEE minus (REE + TEE $\times 0.05)$ (diet-induced thermogenesis (DIT), assumed to be $5 \%$ of TEE) (Table $2)^{42,43}$. The ratio of TEE and REE was the physical activity level (PAL) ${ }^{11,35}$ (Table 2).

\section{Measurement of muscle strength of the legs}

The maximal isometric muscle strength of the musculus quadriceps (Fa max) and the musculus ischiocruralis (Fb max) was measured by computer tensiometry ${ }^{38}$. Both legs of the children were measured at the same time. During the measurement of $\mathrm{Fa} \max$ the children sat and during measurement of $\mathrm{Fb}$ max they lay on their front. The angle between the calf and the thigh amounted to $90^{\circ}$. The impulse of muscle strength was registered automatically by a receptor. The impulse was also sent to a personal computer. The software (Men Power) calculated a curve about the muscle strength registration, which lasted $3 \mathrm{~s}$.

\section{Statistical analyses}

Differences of the continuous data between the groups were tested by Student's $t$-test with Excel 97. The significance of the food-frequency questionnaire data was tested by chi-square test with GraphPad Instat. Statistical significance is denoted by $P<0.05$ or $P<$ 0.01. Data are presented as mean \pm standard deviation (SD) (range in parentheses) or as mean (percentage in parentheses).

\section{Results}

Mean TV viewing time of all children was $1.7 \pm 1.0 \mathrm{~h}$ day $^{-1}$. When compared with children with a TV consumption of $<1 \mathrm{~h}$, children with a high TV consumption had increased body weight, triceps, biceps, abdominal, suprailiacal and subscapular skinfolds, fat mass (FM) and percentage FFM (Table 1). Age, sex distribution, body height, absolute FFM, REE and TEE values were similar between the groups (Tables 1 and 2). Quantitative measures of physical activity, AEE, PAL and time spent with a heart rate above FLEX-HR, were also similar in both groups (Table 2). Regarding attributes of physical fitness, there were no significant group differences in muscle strength (Table 2). $\mathrm{VO}_{2}$ submax and $\mathrm{O}_{2}$-pulse corrected by body weight and body weight ${ }^{0.75}$ were decreased significantly in children of group II; however, there were no differences in RER at rest and during exercise (Table 2). With respect to social factors, parents of children in group II had lower school education than parents in group I (Table 3). There were no group differences in measures of income and membership in sport clubs (Table 3). Regarding nutrition habits, children of group I ate more muesli, but less noodles and spaghetti, when compared with children of group II (Table 4). There were no differences in body composition, REE, TEE, AEE, PAL, aerobic fitness, muscle strength, nutrition habits and socio-demographic factors between children who watched $1-3 \mathrm{~h}$ of TV per day (group IIa: $n=30$ ) and children who watched more than $3 \mathrm{~h}$ of TV per day (group IIb: $n=5$ ) (not significant (NS)).

Regarding gender differences on assessed variables, there were no differences in weight, height, BMI, BMI percentile distribution, skinfolds, FM and FFM (NS). Boys had higher waist/hip ratios $(0.94 \pm 0.07$ vs. $0.89 \pm 0.08$, $P<0.05)$ than girls. $R$ was increased significantly in girls $(735.7 \pm 62.1 \Omega$ vs. $685.9 \pm 55.0 \Omega, P<0.01)$. REE and adjusted REE were higher in boys than in girls $(5.2 \pm 0.9 \mathrm{MJ} / 24 \mathrm{~h}$ vs. $4.8 \pm 0.6 \mathrm{MJ} / 24 \mathrm{~h}, P<0.05$ and $5.3 \pm 0.5 \mathrm{MJ} / 24 \mathrm{~h}$ vs. $5.0 \pm 0.4 \mathrm{MJ} / 24 \mathrm{~h}, P<0.05$, respectively). However TEE, AEE, PAL and time spent with HR $>$ FLEX-HR were similar between both genders (NS). There were also no gender differences in absolute $\mathrm{VO}_{2}$ submax, adjusted $\mathrm{VO}_{2}$ submax, Fa max and $\mathrm{Fb}$ max (NS). The socio-demographic characteristics and nutrition behaviours also did not show gender differences (NS).

\section{Discussion}

An association between TV viewing and overweight has been frequently observed ${ }^{5,16,24,44-46}$. This association was explained by: (1) TV viewing causing overweight and obesity by reduced resting energy expenditure during TV watching $^{8}$; (2) replacement of physical activities by TV, and thus reduced $\mathrm{TEE}^{2}$; (3) a higher consumption of unhealthy food items (like sweets, cakes and fast foods) 
in subjects with increased TV viewing ${ }^{20}$; and/or (4) obesity itself increases TV viewing ${ }^{28}$.

In our population of normal weight and overweight children, those with high TV-viewing time had a higher fat mass and showed a higher prevalence of overweight and obesity (Table 1). There were no differences in REE, TEE, physical activity and muscular fitness between the groups (Table 2).

Contrary to our study design, Klesges et al. measured energy expenditure during TV viewing ${ }^{8}$. These authors found a reduced metabolic rate (of about $13.3 \%$ of REE) during TV watching in obese and normal weight children. They concluded that TV watching reduces energy expenditure and is thus an important risk factor for childhood obesity ${ }^{8}$. However, recalculating our data shows that a reduction of REE during TV viewing by $13.3 \%$ reduces TEE by only $0.4 \%$ (group I) to $1.1 \%$ (group II). This was less than the intra-individual day-to-day variation of TEE $(<6 \%)$ (see Methods) and is unlikely to contribute significantly to daily energy balance.

Dietz et al. examined energy expenditure and physical activity in obese and normal weight girls during different sedentary activities and found no group differences ${ }^{6}$. This was in line with the data of Robinson et al., who also found no association between TV viewing and measures of physical activity ${ }^{23}$. This is also in accordance with our data (Table 2). However, we performed only short-term measurements of energy expenditure (by 24-hour HR monitoring) which may differ from prolonged measurements by the DLW technique (up to 14 days). However, our data are supported by intra-individual comparison showing a CV of repeated HR measurements of below 5\% (Methods). In addition, increased TV viewing was associated with reduced physical fitness.

We found no differences in the consumption of sweets, chips and fast foods between the groups (Table 4). However, within a greater study population of 801 children, we found that children who spent more time viewing TV ate more sweets and fast foods, but less fruit and vegetables ${ }^{26,29}$. This is in line with data of other authors who found that children and adults who watch TV more frequently eat high fat diets ${ }^{20,25}$. These data suggest that nutrition habits associated with TV viewing may add to overweight in subjects watching a lot of TV. However, this is not supported by the present data.

TV-viewing time is influenced by different factors, e.g. the weather, school systems, family structures and social status $^{5,22,23}$. In our study population, children who watched more TV more frequently had parents with a lower level of education (Table 3). The association between TV consumption and social status is in line with previous data of other authors who found a negative relationship between childhood obesity and the social status of their parents ${ }^{5,15,26}$.

In children, activity is a complex phenomenon. TV consumption is only a weak index of inactivity but is associated with increased risk of becoming obese. High TV consumption also reflects an unhealthy lifestyle, which includes reduced physical activity as well as unhealthy food choices (high energy, sugar and fat intakes). We found no relationship between TV viewing and direct measures of energy expenditure, physical activity, and aerobic and muscular fitness. Although the lack of differences between groups could also be explained by the limited sample size and/or the limits of the methods used to assess TEE, we feel that TV viewing more likely reflects an unhealthy lifestyle, contributing to overweight and obesity.

\section{Acknowledgements}

This work was supported by grants from Verein zur Förderung der Rehabilitationsforschung in SchleswigHolstein eV, Lübeck; Wirtschaftliche Vereinigung Zucker, Bonn; Deutsche Forschungsgemeinschaft (MÜ 714-5-1 and 5-2), Selent; and Precon, Bickenbach, Hansa-Tiefkühlmenü GmbH \& Co., Hilter.

\section{References}

1 Davies PSW, Gregory J, White A. Physical activity and body fatness in pre-school children. Int. J. Obes. 1995; 19: 6-10.

2 Deheeger M, Rolland-Cachera MF, Fontvieille AM. Physical activity and body composition in 10 year old French children: linkages with nutritional intake? Int. J. Obes. 1997; 21: 372-9.

3 Fontvieille AM, Kriska A, Ravussin E. Decreased physical activity in Pima Indian compared with Caucasian children. Int. J. Obes. 1993; 17: 445-52.

4 Hill JO, Peters JC. Environmental contributions to the obesity epidemic. Science 1998; 280: 1371-4.

5 Anastassea-Vlachou K, Fryssira-Kanioura H, PapathanasiouKlontza D, Xipolita-Zachariadi A, Matsaniotis N. The effects of television viewing in Greece, and the role of the paediatrician: a familiar triangle revisited. Eur. J. Pediatr. 1996; 155: 1057-60.

6 Dietz WH, Bandini LG, Morelli JA, Peers KF, Ching PL. Effect of sedentary activities on resting metabolic rate. Am.J. Clin. Nutr. 1994; 59: 556-9.

7 Dietz WH, Gortmaker SL. Do we fatten our children at the television set? Obesity and television viewing in children and adolescents. Pediatrics 1985; 75: 807-12.

8 Klesges RC, Shelton ML, Klesges LM. Effects of television on metabolic rate: potential implications for childhood obesity. Pediatrics 1993; 92(2): 281-6.

9 Maffeis C, Zaffanello M, Schutz Y. Relationship between physical inactivity and adiposity in prepubertal children. $J$. Pediatr. 1997; 191(2): 288-92.

10 Goran MI, Reynolds KD, Lindquist CH. Role of physical activity in the prevention of obesity in children. Int.J. Obes. 1999; 23(3): 18-33.

11 Westernerp KR. Obesity and physical activity. Int. J. Obes. 1999; 23: 59-64.

12 Haskell WL, Yee MC, Evans A, Irby PJ. Simultaneous measurement of heart rate and body motion to quantitate physical activity. Med. Sci. Sports Exerc. 1993; 25: 109-15.

13 Livingstone MBE. Energy expenditure and physical activity in relation to fitness in children. Proc. Nutr. Soc. 1994; 53: 207-21.

14 Maffeis C, Schena F, Zaffanello M, Zoccante L, Schutz Y, 
Pinelli L. Daily energy expenditure in free-living conditions in obese and non-obese children: comparison of doubly labelled water $\left({ }^{2} \mathrm{H}_{2}{ }^{18} \mathrm{O}\right)$ method and heart-rate monitoring. Int. J. Obes. 1995; 19: 671-7.

15 Murgatroyd PR, Shetty PS, Prentice AM. Techniques for the measurement of human energy expenditure: a practical guide. Int. J. Obes. 1993; 17: 549-68.

16 Anderson RE, Crespo CJ, Bartlett SJ, Cheskin LJ, Pratt M. Relationship of physical activity and television watching with body weight and level of fatness among children. JAMA 1998; 279: 938-42.

17 Dietz WH, Gortmaker SL. TV or not TV: fat is the question. Pediatrics 1993; 91: 499-500.

18 Glenmark B, Hedberg G, Jansson E. Prediction of physical activity level in adulthood by physical characteristics, physical performance and physical activity in adolescence: an 11-year follow-up study. Eur. J. Appl. Physiol. 1994; 69 530-8.

19 Hughes JM, Li L, Chinn S, Rona RJ. Trends in growth in England and Scotland, 1972 to 1994. Arch. Dis. Child. 1997; 76: $182-9$.

20 Jeffery RW, French SA. Epidemic obesity in the United States: are fast foods and television viewing contributing? Am. J. Public Health 1998; 88: 277-80.

21 Ravussin E, Bogardus C. Relationship of genetics, age, and physical fitness to daily energy expenditure and fuel utilisation. Am. J. Clin. Nutr. 1989; 49: 968-75.

22 DuRant RH, Baranowski T, Johnson M, Thompson WO. The relationship among television watching, physical activity, and body composition of young children. Pediatrics 1994; 94(4): 449-55

23 Robinson TN, Hammer LD, Killen JD, Kraemer HC, Wilson DM, Hayward C, Taylor CB. Does television viewing increase obesity and reduce physical activity? Crosssectional and longitudinal analyses among adolescent girls. Pediatrics 1993; 91: 273-80.

24 Hernandez B, Gortmaker SL, Golditz GA, Peterson KE, Laird NM, Parra-Cabrera E. Association of obesity with physical activity, television programs and other forms of video viewing among children in Mexico City. Int. J. Obes. 1999; 23: 845-54.

25 Obarzanek E, Schreiber GB, Crawford PB, Goldman SR, Barrier PM, Frederick MM, Lakatos E. Energy intake and physical activity in relation to indexes of body fat: the National Heart, Lung, and Blood Institute Growth and Health Study. Am. J. Clin. Nutr. 1994; 60: 15-22.

26 Müller MJ, Mast M, Koertzinger I, Grund A, Langnäse K. Physical activity and diet in 5 to 7 years old children. Public Health Nutr. 1999; 2(3a): 443-4.

27 Story M, Faulkner P. The prime time diet: a content analysis of eating behaviour and food messages in television program content and commercials. Am. J. Public Health 1990; 80: 738-40.

28 Robinson TN. Does television cause childhood obesity? JAMA 1998; 279: 959-60.

29 Mast M, Körtzinger I, Müller MJ. Nutrition behaviour and status of children in Kiel aged 5 to 7 years. Akt. Ernähr. Med. 1998; 23: 282-8.
30 Mast M, Körtzinger I, König E, Müller MJ. Gender differences in fat mass of 5-7 year old children. Int. J. Obes. 1998; 22: 878-84.

31 Hesse V. Wachstum und Entwicklung. In: Meng W, Ziegler R, eds. Endokrinologie-Grundlagen Klinik Praxis. Jena/ Stuttgard/Lübeck/Ulm: Fisher Verlag, 1997; 623.

32 Müller MJ. Ernäbrungsmedizinische Praxis. Berlin: Springer-Verlag, 1998; 40-82.

33 Goran MI, Driscoll P, Johnson R, Nagy TR, Hunter G. Crosscalibration of body composition techniques against dualenergy x-ray absorptiometry in young children. Am. J. Clin. Nutr. 1996; 63: 299-305.

34 Müller MJ, Bosy-Westphal A, Grund A, Selberg O. 'Standardisation' of metabolic parameters: are there suitable reference values for resting energy expenditure? Akt. Ernähr. Med. 1999; 24: 174-81.

35 Grund A, Vollbrecht H, Frandsen W, Krause H, Siewers M, Rieckert H, Müller MJ. Messung des 24-h-Energieverbrauchs mit 'heart rate monitoring' bei Kindern und Erwachsenen. Akt. Ernähr. Med. 1999; 24: 129-37.

36 Schulz S, Westerterp KR, Brück K. Comparison of energy expenditure by the doubly labelled water technique with energy intake, heart rate, and activity recording in man. $\mathrm{Am}$. J. Clin. Nutr. 1989; 49: 1146-54.

37 Neumann G, Schüler KP. Sportmedizinische Funktionsdiagnostik. Leipzig: Ambrosius Borth-Verlag, 1994; 44-6.

38 Zhang YY, Johnson MC, Chow N, Wassermann K. The role of fitness on $\mathrm{VO}_{2}$ and $\mathrm{VCO}_{2}$ kinetics in response to proportional step increases in work rate. Eur. J. Appl. Physiol. 1991; 63: 94-100.

39 Rerybrouck T, Mertens L, Schepers D, Vinckx J, Gewillig M. Assessment of cardiorespiratory exercise function in obese children and adolescents by body mass-independent parameters. Eur. J. Appl. Physiol. 1997; 75: 478-83.

40 Grund A, Vollbrecht H, Frandsen W, Krause H, Siewers M, Rieckert H, Müller MJ. No effect of gender on different components of daily energy expenditure in free living prepubertal children. Int. J. Obes. 2000; 24: 1-7.

41 Grund A, Dilba B, Forberger K, Krause H, Siewers M, Rieckert $H$, Müller MJ. Relationships between physical activity, physical fitness, muscle strength and nutritional state in 5- to 11-year-old children. Eur. J. Appl. Physiol. 2000; 82: 425-38.

42 McArdle WD, Katch FI, Katch VL. Exercise Physiology, Energy, Nutrition, and Human Performance. Philadelphia, PA/London: Lea \& Febiger, 1991; 452-5.

43 Spurr GB, Prentice PD, Murgatroyd PR, Goldberg MS, Reina JC, Christman NT. Energy expenditure from minute-byminute heart rate recording: comparison with indirect calorimetry. Am. J. Clin. Nutr. 1988; 48: 552-9.

44 Gortmaker SL, Dietz WH, Cheung LWY. Inactivity, diet, and the fattening of America. J. Am. Diet. Assoc. 1990; 90: 124755.

45 Salbe AD, Fontvieille AM, Harper IT, Ravussin E. Low levels of physical activity in 5-year-old children. J. Pediatr. 1997; 423-9.

46 Mamalakis G, Kafatos A. Prevalence of obesity in Greece. Int. J. Obes. 1996; 20: 488-92. 